\title{
Displasia ectodérmica, ectrodactilia e fissura lábio-palatal: manifestações oculares da síndrome em relato de caso
}

\author{
Ectodermal dysplasia, ectrodactylyand clefting syndrome: \\ ocular manifestations of this syndrome in a case report
}

\author{
Sandra Flávia Fiorentini de Almeida ${ }^{1}$ \\ Helena Parente Solari ${ }^{2}$
}

Trabalho realizado no Setor de Córnea e Doenças Externas do Departamento de Oftalmologia da Universidade Federal de São Paulo - UNIFESP.

${ }^{1}$ Pós-graduanda do Departamento de Oftalmologia da Universidade Federal de São Paulo - UNIFESP - São Paulo (SP) - Brasil.

${ }^{2}$ Pós-graduanda do Departamento de Oftalmologia da UNIFESP - São Paulo (SP) - Brasil.

Endereço para correspondências: Sandra Flávia Fiorentini de Almeida. Av. Comendador Adibo Ares, 1021

- São Paulo (SP) CEP 05613-001

E-mail: sandra.flavia@click21.com.br

Recebido para publicação em 30.08.2005

Última versão recebida em 04.01.2006

Aprovação em 10.03.2006

Nota Editorial: Depois de concluída a análise do artigo sob sigilo editorial e com a anuência do Dr. Paulo Ricardo de Oliveira sobre a divulgação de seu nome como revisor, agradecemos sua participação neste processo.

\section{RESUMO}

Descrição de um caso da síndrome de displasia ectodérmica, ectrodactilia e fissura lábio-palatal (EEC), doença rara com importante acometimento ocular. Paciente de 26 anos, com queixa de dor, fotofobia e baixa acuidade visual no olho esquerdo há três dias, submetida à investigação genética, após exames físico e oftalmológico completos. Foi diagnosticado síndrome EEC e identificadas todas as alterações sistêmicas e oculares. Apresentava uma úlcera paracentral estéril no olho esquerdo, com dificuldades de cicatrização devido às alterações oculares próprias da síndrome (alteração do filme lacrimal, triquíase, ausência de glândulas de Meibomius, entre outras). Foi feita descrição das alterações oculares nessa síndrome rara, para que haja tratamento preventivo e diminuam os riscos de baixa de acuidade visual em pacientes que recebam esse diagnóstico genético.

Descritores: Displasia ectodérmica; Fenda labial; Fissura palatina; Anormalidades múltiplas; Manifestações oculares; Doenças da córnea; Síndrome

\section{INTRODUÇ̃̃̃O}

Displasia ectodérmica, ectrodactilia e fissura lábio-palatal, é a tríade que corresponde à síndrome EEC 1, desordem genética de herança auto-sômica dominante, com penetrância incompleta e expressividade variável ${ }^{(1)}$.

Em 1936, Cockayne a reconheceu pela primeira vez como sendo uma síndrome, com a tríade: ectrodactilia, displasia ectodermal e fenda palatina ${ }^{(2)}$. A ectrodactilia corresponde à deformidade das mãos e pés ${ }^{(2)}$. A displasia ectodermal compreende hipoplasia das unhas, cabelos finos e esparsos, microdontia ou anodontia, anormalidades das glândulas sudoríparas e em outros órgãos que contenham alguma origem ectodérmica, como rins, coração, ouvido e olhos ${ }^{(2)}$. A fenda palatina pode ser somente labial ou afetar todo o palato ${ }^{(2)}$.

Menos de 200 casos foram descritos ${ }^{(3)}$. Apesar da escassez de publicações oftalmológicas sobre essa síndrome, o acometimento ocular é muito freqüente ${ }^{(4-5)}$ e será descrito nesse relato de caso.

\section{RELATO DE CASO}

Paciente de 26 anos, feminina, branca, solteira, profissão do lar, natural e procedente de São Paulo, procurou consulta oftalmológica devido à dor, fotofobia intensa e baixa acuidade visual no olho esquerdo por três dias.

Referia outros episódios anteriores de dor ocular e baixa acuidade visual no mesmo olho, mas não com tanta intensidade e que melhoraram com o uso de colírios antibióticos. 
Apresentava episódios repetitivos de furunculose nos membros inferiores e superiores e candidíase. Informou ter sido submetida à extração de todos os dentes, cirurgia de fenda palatina, de ouvidos e de mãos na infância, devido às malformações congênitas.

Nasceu de parto cesárea, a termo, após gestação não complicada de mãe primigesta com 23 anos.

Pais saudáveis e sem consangüinidade, não há relato de outro caso na família.

\section{Quadro clínico}

Fácies sindrômica (Figura 1) que compreendia hipoplasia maxilar, base nasal larga e fenda palatina.

Ectrodactilia de mãos (Figura 2) e pés, cabelo fino e esparso, pele seca, unhas descamativas, fenda palatina corrigida cirurgicamente, em uso de prótese dentária.

Exame oftalmológico: Ambos os olhos apresentavam pálpebras com triquíase, ausência de glândulas de Meibomius nas pálpebras superiores e inferiores (Figura 3), conjuntivas sem alterações, córneas com opacidade leve estromal difusa, sem edema, segmento anterior, íris, cristalino e fundo de olho normais. Além dessas alterações, o olho esquerdo apresentava úlcera corneana paracentral inferior de aproximadamente $3 \mathrm{~mm}$ por $4 \mathrm{~mm}$ e neovasos inferiores profundos e superficiais (Figura 4).

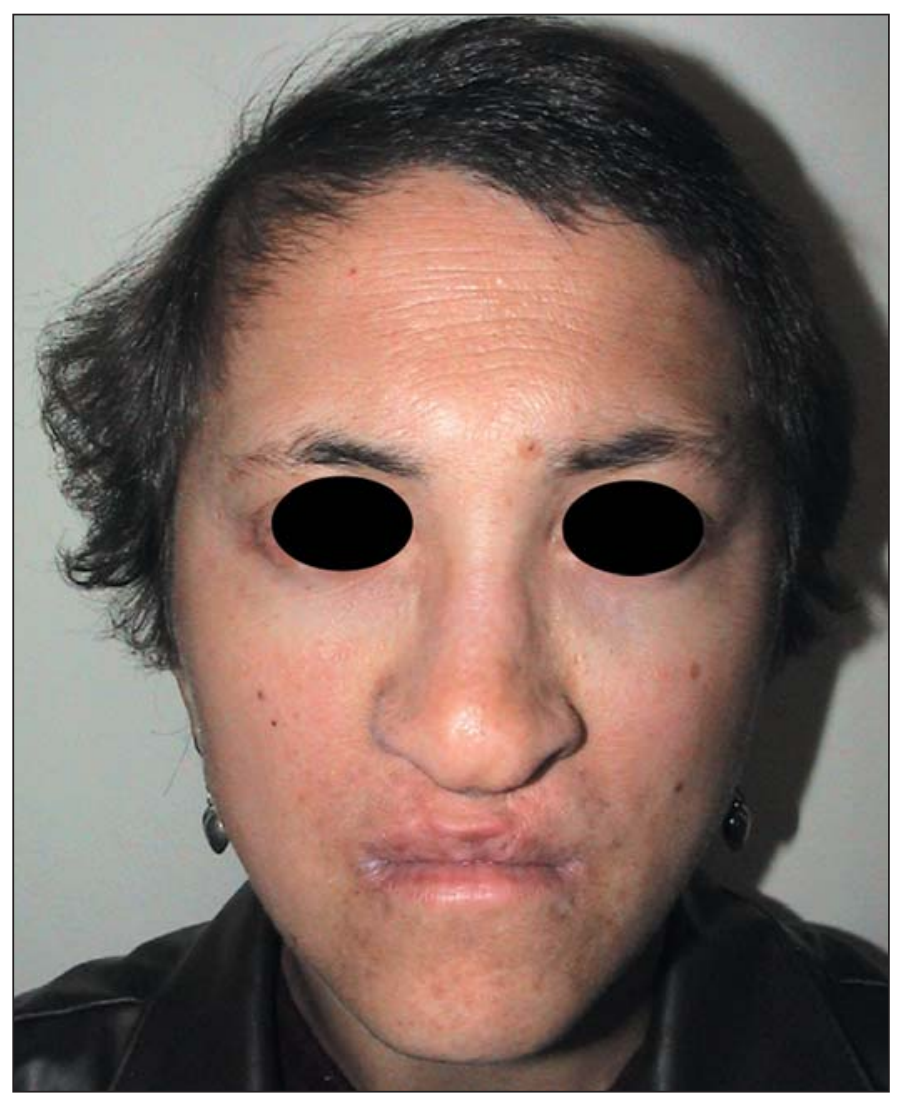

Figura 1 - Fáscies sindrômica (base nasal larga, hipoplasia maxilar, cicatriz de cirurgia de fenda labial)
Sensibilidade corneana bilateral foi normal.

A paciente estava fazendo uso de ofloxacino $0,3 \%$ por 5 semanas sem melhora, foi interrompido o tratamento por 24 horas, colhido material para bacterioscopia e cultura e como resultado, não foi encontrado nenhum agente patogênico.

Para essa úlcera estéril, foram prescritos lubrificantes oculares, cicloplégico, lente de contato terapêutica e colírio para antibioticoprofilaxia, entretanto a paciente apresentou-se refratária ao uso da lente e à tarsorrafia proposta.

Permaneceu em acompanhamento, com o tratamento acima e após aproximadamente 30 dias houve cicatrização da úlcera.

Apresentou olho seco severo, com menisco lacrimal muito diminuído, BUT 3s, teste de Schirmer I de $6 \mathrm{~mm}$, leve punctata inferior bilateral corando com fluoresceína.

A acuidade visual atual foi de 1,0 no olho direito e 0,3 no olho esquerdo, com correção, em uso de metilcelulose $0,5 \%$ colírio de duas em duas horas e ácido poliacrílico 2 mg gel à noite. Há um mês foi submetida à cirurgia para correção da triquíase.

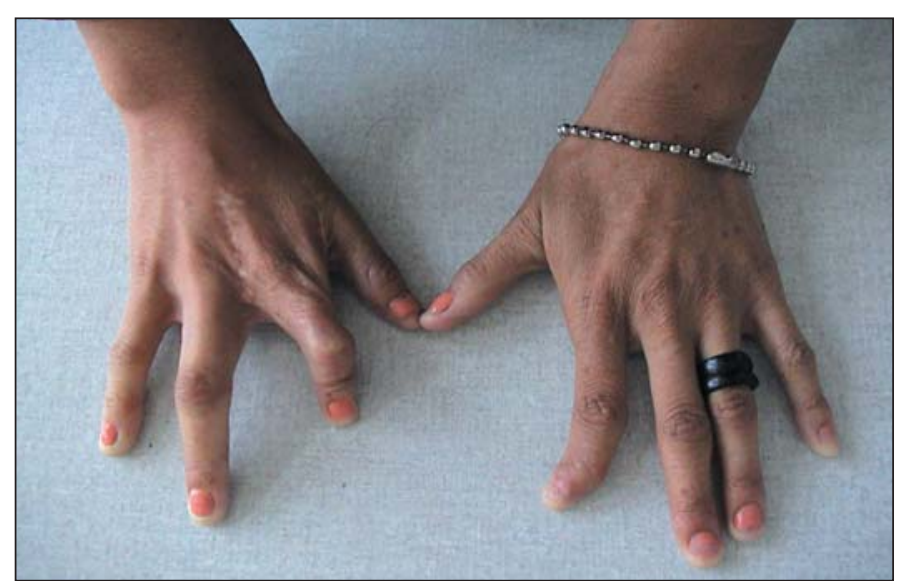

Figura 2 - Ectrodactilia de mãos

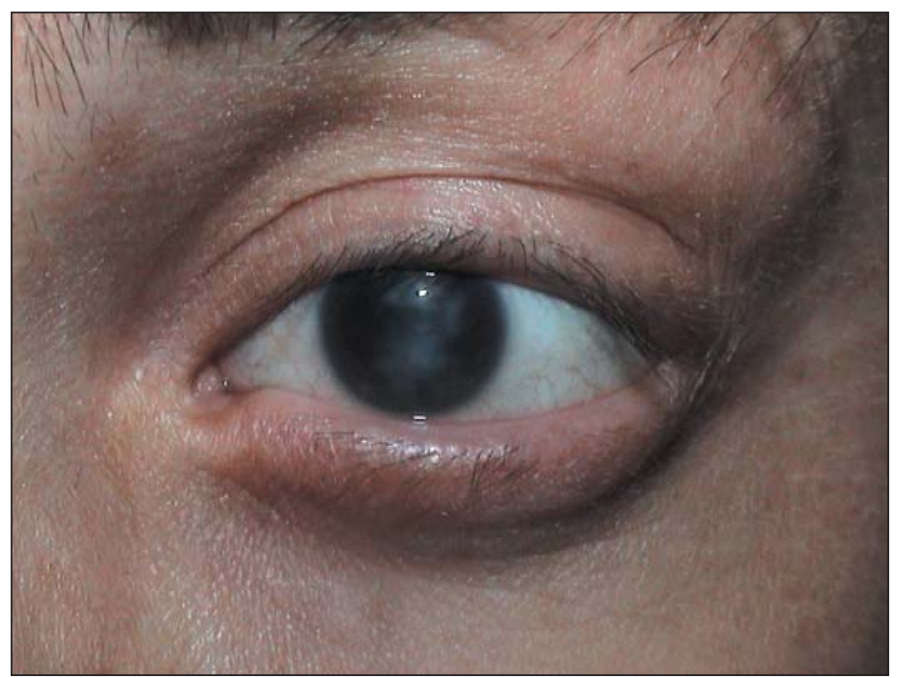

Figura 3 - Triquíase, ausência de glândulas de Meibomius superior e inferiormente, córnea com leucoma estromal difuso 
Atualmente, permanece em acompanhamento multidisciplinar, após o diagnóstico clínico de síndrome EEC1 pela Genética e identificação do gene afetado (7q11.2-q21.3).

\section{DISCUSSÃO}

As complicações oculares da síndrome EEC podem ser muito incapacitantes, podendo levar à diminuição severa da acuidade visual por opacidade de córnea ${ }^{(5)}$.

Anomalias do sistema de drenagem lacrimal são comuns, presentes em aproximadamente $85 \%$. Variam da ausência ou atresia do ponto lacrimal até o desenvolvimento incompleto ou ausência dos canalículos, saco lacrimal ou ductos nasolacrimais $^{(4)}$.

Ceratopatias também são comuns, com típico início precoce, progressão de infiltrado estromal e crescimento de pannus com neovascularização, opacidades e afinamentos ${ }^{(5)}$.

Erosões recorrentes e ulcerações têm sido documentadas, como no relato do caso descrito ${ }^{(5)}$.

Outras manifestações oculares descritas foram: fotofobia, telecantus, blefarites, conjuntivites, microftalmia e anoftalmia, triquíase, entrópio, ausência ou escassez de sobrancelhas e cílios e redução da produção de lágrima e da secreção das glândulas de Meibomius, quando presentes ${ }^{(6)}$.

Há aproximadamente de 30 a 40 glândulas de Meibomius em pálpebra superior e de 20 a 40 e pálpebra inferior de indivíduos normais. Deficiências congênitas dessa glândula têm sido discutidas, mas a ausência completa delas é muito rara. A síndrome EEC pode compreender tanto a redução do número das glândulas de meibomius, quanto a completa ausência ${ }^{(7)}$.

Úlceras de córnea podem ser resultado de disfunção das glândulas de Meibomius e também devido a blefarite recorrente que é mais comum na infância e que melhora após cirurgias para aumentar a drenagem lacrimal ${ }^{(8)}$.

A base patológica para a ceratopatia em pacientes com EEC síndrome é provavelmente multifatorial ${ }^{(9)}$.

Tecidos de origem ectodérmica, e mesodérmica podem ser afetados. Baum and Bull dizem que as alterações corneanas são devido a defeitos ectodérmicos primários, desde que a ceratopatia inicie na porção superior da córnea, protegida pela pálpebra, enquanto a córnea exposta pela fenda palpebral está normal $^{(9)}$.

A ausência de glândulas meibomianas e a redução das células caliciformes conjuntivais resultam em instabilidade do filme lacrimal, levando a uma alteração na superfície epitelial ocular. Em pacientes com reduzida produção de lágrima e infecções recorrentes devido a obstrução do canal lacrimal, a córnea pode ser severamente comprometida por opacidades ${ }^{(10)}$.

\section{CONCLUSÃO}

Após investigação genética e diagnóstico de EEC1, identificando-se o gene afetado e seu locus (7q11.2-q21.3), a orientação deve ser uma abordagem multidisciplinar.
A síndrome EEC deve compreender a avaliação dos seguintes: cirurgia plástica (pela ectrodactilia), nefrologia (para investigação de malformações e refluxo vesico-ureteral), oftalmologia ${ }^{(11)}$, otorrinolaringologia (pela fenda palatina), dermatologia $^{(12)}$ (pele, cabelo e unhas comprometidas), psicologia, odontologia ${ }^{(13)}$ (pela anodontia ou hipodontia) e genética (para aconselhamento familiar após diagnóstico genético).

Devido às possíveis complicações oculares que podem levar à diminuição da acuidade visual, a avaliação oftalmológica completa é imperativa, assim como o conhecimento das possíveis alterações oculares pelo oftalmologista.

O tratamento profilático deve ser instituído o mais precocemente possível. Os recursos para melhorar as condições da superfície ocular são desde lubrificantes, correção de triquíase e entrópio, cirurgia de vias lacrimais, até tarsorrafia, todas as condutas sendo realizadas conforme a gravidade de cada caso, com a finalidade de minimizar o comprometimento corneano.

\section{ABSTRACT}

A case of ectodermal dysplasia, ectrodactyly and clefting syndrome (EEC), a rare disease with an important ocular impairment and with scarce literature. Patient, 26 years old with complaints of pain, with photophobia and low visual acuity in the left eye for three days. The patient was submitted to a genetic investigation after complete physical and ophthalmologic examinations. EEC syndrome was diagnosed and all systemic and ocular modifications identified. The patient presented a scar in the left eye, with difficulties in healing due to ocular damage caused by the syndrome (lack of tear film, trichiasis, Meibomius gland absence, among others). The ocular modifications in this rare syndrome were described in order to institute preventive treatment and to reduce the risks of low visual acuity in patients who receive this genetic diagnosis.

Keywords: Ectodermal dysplasia; Cleft lip; Cleft palate; Abnormalities, multiple; Eye manifestations; Corneal diseases; Syndrome

\section{REFERÊNCIAS}

1. OMIM - Online Mendelian Inheritance in Man [database on the Internet]. Baltimore: Johns Hopkins University; c 2006. [cited 2006 Feb 27]. Available from: www.ncbi.nlm.nih.gov/OMIM

2. Ireland IA, Meyer DR. Ophthalmic manifestations of ectrodactyly-ectodermal dysplasia-clefting syndrome. Ophthal Plast Reconstr Surg. 1998;14(4):295-7.

3. Roelfsema NM, Cobben JM. The EEC syndrome: a literature study. Clin Dysmorphol. 1996;5(2):115-27.

4. Bonnar E, Logan P, Eustace P. Absent meibomian glands: a marker for EEC syndrome. Eye. 1996;10(Pt 3):355-61.

5. McNab AA, Potts MJ, Welham RA. The EEC syndrome and its ocular manifestations. Br J Ophthalmol. 1989;73(4):261-4.

6. Pries C, Mittelman D, Miller M, Solomon LM, Pashayan HM, Pruzansky S. The EEC syndrome. Am J Dis Child. 1974;127(6):840-4.

7. Mondino BJ, Bath PE, Foos RY, Apt L, Rajacich GM. Absent meibomian glands in the ectrodactyly, ectodermal dysplasia, cleft lip-palate syndrome. Am J Ophthalmol. 1984;97(4):496-500. 
8. Buss PW, Hughes HE, Clarke A. Twenty-four cases of the EEC syndrome: clinical presentation and management. J Med Genet. 1995;32(9):716-23.

9. Baum JL, Bull MJ. Ocular manifestations of the ectrodactyly, ectodermal dysplasia, cleft lip-palate syndrome. Am J Ophthalmol. 1974;78(2):211-6.

10. Matsumoto Y, Dogru M, Goto E, Endo K, Tsubota K. Increased tear evaporation in a patient with ectrodactyly-ectodermal dysplasia-clefting syndrome. Jpn J Ophthalmol. 2004;48(4):372-5.

11. Ferreira RC, Panazzolo AR, Rymer S. Manifestações oculares da síndrome
EEC: revisão da literatura e relato de caso. Arq Bras Oftalmol. 1992;55(3): 117-23.

12. Trüeb RM, Tsambaos D, Spycher MA, Muller J, Burg G. Scarring folliculitis in the ectrodactyly-ectodermal dysplasia-clefting syndrome. Histologic, scanning electron-microscopic and biophysical studies of hair. Dermatology. 1997; 194(2):191-4.

13. Ulukapi I, Bilgin T, Yalcin S. EEC syndrome (ectrodactyly-ectodermal dysplasia-clefting): a clinical case report. ASDC J Dent Child. 2001;68(5-6):350-2, 302.

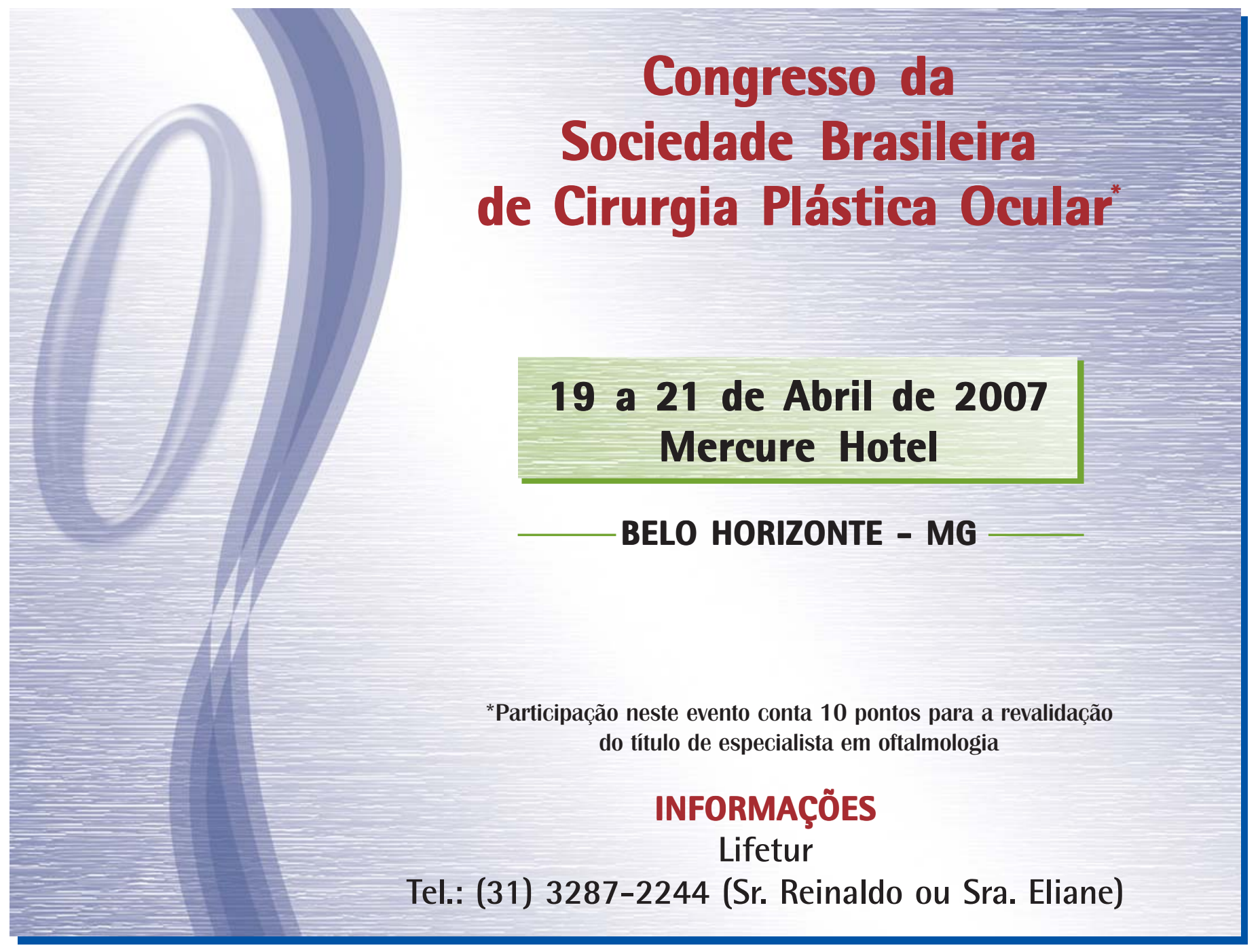

